\title{
The recognition of childhood thyroid cancer as a consequence of the Chernobyl accident: an allegorical tale of our time?
}

\author{
Keith Baverstock
}

J R Soc Med 2007;100:407-409

\section{INTRODUCTION}

I begin with something said by the physicist Edward Lorenz: 'let our premise be that we should believe what is true even if it hurts, rather than what is false even if that makes us happy'. ${ }^{1}$ Lorenz is often called the 'father of chaos', since he was the first to note that some complex dynamic systems had an exquisitely sensitive dependence on 'initial conditions'. This meant that their evolution could not be predicted over long periods of time. The weather is one of those systems. He made the above statement in the context of discussing whether humans truly have free will, but I have found another context in which it is equally applicable: I think it a very relevant observation on how human nature is able to believe something even in the face of overwhelming evidence to the contrary.

In this paper I illustrate how an important truth emerged from the chaos of the Chernobyl accident over the period 1992-1998, and what factors might have influenced this process; I ask whether there are any lessons to be learnt from this experience; and finally I suggest five truths that I discern from the accident and its consequences.

\section{CHILDHOOD THYROID CANCER AND CHERNOBYL}

The first claims of an increase in childhood thyroid cancer came from Minsk in Belarus. I became aware of them late in 1991 when I was informed by a colleague that two Belarusian doctors had made such claims at a meeting in Germany in October 1991. I had recently joined the World Health Organization (WHO), and it seemed to me and my colleague to be essential that the claims were properly evaluated. In collaboration with the European Commission (EC) an expert group meeting was held on 6 January 1992 and the two Belarusian doctors were invited to present their evidence. It was clear at that stage that something was amiss, but the quality of the pathological and histological slides were such as to preclude firm diagnoses in many of the cases presented. The expert group decided that there

Department of Environmental Science, University of Kuopio, PL 1627 70211, Kuopio, Finland

Email: keith.baverstock@uku.fi should be a joint WHO/EC mission to Minsk to investigate the matter further. In the event the EC withdrew and the mission, in July 1992, was a purely WHO mission comprising Professor Aldo Pinchera, Professor Sir Dillwyn Williams and myself, funded by the Swiss Federal Office of Health.

There were many reasons to doubt that the claims of an increase related to the Chernobyl accident might be sound. It was rather soon to see cancer arising from an exposure only five years in the past; in general, latencies for solid cancer are a minimum of ten years. It appeared that there were some 100 cases diagnosed in children, which seemed unlikely given the rarity of the disease. The only source of exposure that could have been responsible for doses that might have caused large increases in thyroid cancer was radioactive iodine, and there was strong epidemiological and a body of animal experimental evidence supporting the non-carcinogenic nature of this isotope despite its radioactivity. That there was a high degree of scepticism that any increase in thyroid cancer so soon after the accident was therefore not surprising.

On the other hand, in one afternoon in one hospital in Minsk the WHO mission saw 11 children with thyroid cancer, aged between four and 13, with evidence of recent neck surgery, together with histological evidence of 25 thyroid cancer cases operated on in Minsk in the previous six months. Childhood thyroid cancer occurs naturally in about one child per million children per year. Belarus has a total population of ten million, with approximately 2.25 million children, so that it was extraordinary to find so many cases in one place at one time.

In September 1992 two letters appeared, one from the Belarusian doctors presenting their evidence, ${ }^{2}$ and the second from the WHO mission and a group of Swiss scientists confirming it. ${ }^{3}$ These letters were treated with considerable scepticism, particularly by those with a pronuclear view and most notably by staff of the International Atomic Energy Agency (IAEA), demanding irrefutable evidence that the cases were associated with the radioactive iodine released from the accident. In retrospect it is quite astonishing that the IAEA, the UN body that regards itself as primarily responsible for safety as far as ionizing radiation is 
concerned-indeed, the lead agency in the development and enforcement of the Basic Safety Standards - should, without any investigation of the situation, dismiss the claims.

An alternative response, perhaps more objectively based, was that as the thyroid doses from radioactive iodine ranged up to several Gray, a reasonable precautionary approach would be to assume that radioactive iodine was the cause of the increase until such time as another more credible explanation was revealed by further research. These two diametrically opposed views dominated the discussion from 1992 to 1996 , and the negative view effectively delayed much needed humanitarian aid and assistance reaching the victims.

\section{THE DEBATE}

In 1995 a meta-analysis of several small epidemiological studies of the effect of externally generated $\mathrm{X}$ ray exposure of the thyroid revealed that young children were at a much greater risk of adverse effects in the thyroid than adults. ${ }^{4}$ This explained why the epidemiological evidence had shown no effect for radioactive iodine. The epidemiological studies were on patients treated diagnostically or therapeutically with ${ }^{131}$ I in Sweden. ${ }^{5}$ Although the population under study was large, the number of children so treated was quite small; too small, in fact, to detect any increase in childhood thyroid cancer.

A number of animal experiments were also cited to support the argument that ${ }^{131}$ I was much less carcinogenic to the thyroid than external radiation, but one experiment in particular did show that ${ }^{131} \mathrm{I}$ could be as carcinogenic as external radiation to the thyroid in rats. ${ }^{6}$ This was significantly larger than those that showed a lesser effect and it was subsequently concluded that it was the only study with sufficient statistical power. The findings of this study were confirmed by an independent review carried out under the auspices of the United States Department of Energy, but the report of the review was not published.

The early appearance of the cancers was another puzzling feature; however, subsequent research showed that this could be understood simply in terms of the size of the outbreak. In respect of the age dependence of thyroid cancer, the growth of the thyroid has to be borne in mind. During childhood the thyroid grows with the rest of the body, but once adulthood is reached the only need for thyroid growth is to replace lost cells. In adults, therefore, thyroid cells have very little capacity to divide further, and cells that cannot divide cannot become malignant. This, together with the increased uptake of radioiodine in children, provides us with a good biological understanding of why the immature thyroid is so sensitive to the effects of radiation and the adult thyroid relatively insensitive.
In 1998 it was shown that the Chernobyl cancers were occurring at about the same rate in relation to absorbed dose as those induced with $\mathrm{X}$ rays in children, ${ }^{7}$ which has since been confirmed. ${ }^{8}$

Thus the truth has emerged: the great increase in thyroid cancer as a result of exposure to fallout has now been conclusively demonstrated by epidemiology, the predominant features of how the thyroid cancer was expressed in the exposed population can be understood in terms of basic biology, and the earlier anomalies have been explained. This illustrates the extraordinary power of science as an investigative public-health tool.

\section{THE RESPONSE}

Who now was not happy? The pro-nuclear lobby did not want the truth to emerge, although I suspect they had a very good idea of the importance of ${ }^{131}$ I a long time ago. Iodine, a prolific fission product, is highly volatile and its release from fractured fuel rods at high temperature cannot be prevented. At that time an entirely unconnected issue, the exposure of the US population to significant thyroid doses - and therefore the risk of thyroid disease-from the above-ground testing of nuclear weapons in Nevada between 1951 and 1962, was under investigation by the National Cancer Institute (NCI) at the request of Congress. A re-evaluation of the dosimetry of the iodine fallout throughout the US was complete by the late 1980s, and showed that doses were much higher than previous studies had indicated. If it were the case that ${ }^{131} \mathrm{I}$ was not carcinogenic this finding would have been of little consequence. The NCI's report was leaked to a newspaper - and the emerging evidence of increased disease as a result of exposure to ${ }^{131}$ I was not at all welcome in the USA.

Since the beginning of 2003 the IAEA, WHO and UN Development Programme have been responsible for the conduct of the Chernobyl Forum. In September 2005 the draft Health Report of the Forum was produced and launched with a press release which contained the statement: 'a total of up to 4000 people could eventually die of radiation exposure from the Chernobyl nuclear power plant accident nearly 20 years ago'. Looking more deeply into that report, it will be found that the figure deduced in the body of the report is not 4000 but closer to 9000. Looking even more closely it will be found that this figure excludes any consequences of the collective dose from outside the main affected areas of Belarus, Ukraine and the Russian Federation, which received less than 20\% of the total collective dose. ${ }^{9}$ In fact, if the total global collective dose of 600,000 person $\mathrm{Sv}$ is used according to the same criteria as are employed to reach the estimates of 
4000 or 9000 , the projected fatal cancer yield of the accident is $60,000 .{ }^{10}$

Recently the IAEA were reported as saying that they stand by the 4000 figure because the calculation for the additional 5000 is so uncertain that both organizations 'consider it insignificant'. ${ }^{11}$ However, WHO says it issued a statement in April 2006 'to correct the imprecisions', saying that there may be up to 9000 deaths. By ignoring collective dose in estimating the number of fatalities, both WHO and IAEA have in effect assumed a threshold below which there is no effect. Both are governed by the Basic Safety Standards published by the IAEA in 1996,12 which explicitly state that there is no evidence to support a threshold.

This incident typifies one side of a distasteful, dangerous and dishonest situation in which science becomes corrupted for political ends. However, there is another side: the exaggeration of the effects of the accident by exploiting our lack of secure knowledge upon which to make forecasts of damage, or in attributing effects not likely to be due to the radiation from the accident. Both these dishonest features, which have characterized the response to the accident, must be in no small part the cause of the psychological effects that have blighted the lives of millions of those exposed to the fallout. ${ }^{13}$

\section{CONCLUSION}

My five truths about Chernobyl are thus:

- It is still too early to have seen all the health consequences of the accident;

- We do not have the theoretical basis upon which to make confident predictions of the totality of its health impact;

- In spite of the size of the thyroid cancer outbreak, it is arguable that the most significant effect was psychosocial, which was only partially inflicted by radiation and could possibly have been avoided or at least minimized had the response to the accident been more honest;

- The international community has been a distinctly mixed blessing to the afflicted, often more concerned with their own agendas than genuinely concerned with their plight;

- The outcome could have been very different if there had been a will to make it so; and there remains an overwhelming case to investigate the consequences of the accident in a coherent and rational way.
I believe, and I hope you agree, that these truths are by and large what we might call absolute, dependent on the evidence that is there to be seen by all, or at least all those who are prepared to see. It is fashionable in some circles to believe that truth is only relative - that there are no absolutes. So I end with words from what many may regard as an unlikely source, at least for me to quote, a statement made in June 2005 by Pope Benedict XVI: 'relativism, recognizing nothing as definitive, leaves as the ultimate criterion of truth only the self with its desires'.

Competing interests None declared.

\section{Guarantor KB.}

Acknowledgments This paper is based on a presentation to the Medact conference marking the 20th anniversary of the Chernobyl accident, London, 22 April 2006.

\section{REFERENCES}

1 Lorenz EN. The Essence of Chaos. London: UCL Press, 1993

2 Kazakov VS, Demidchik EP, Astakhova LN. Thyroid cancer after Chernobyl. Nature 1992;359:21

3 Baverstock K, Egloff B, Pinchera A, Ruchti C, Williams D. Thyroid cancer after Chernobyl. Nature 1992;359:21-2

4 Ron E, Lubin JH, Shore RE, et al. Thyroid cancer after exposure to external radiation: a pooled analysis of seven studies. Radiat Res 1995; 141:259-77

5 Holm L-E. Thyroid cancer after diagnostic and therapeutic use of radionuclides; a review of the association. In: Thomas $\mathrm{G}$, Williams ED, Karaoglou A (eds). Radiation and Thyroid Cancer. Singapore: World Sceintific, 1999:13-20

6 Lee W, Chiacchierini RP, Shleien B, Telles NC. Thyroid tumors following ${ }^{131} \mathrm{I}$ or localized $\mathrm{X}$ irradiation to the thyroid and pituitary glands in rats. Radiat Res 1982;92:307-19

7 Jacob P, Goulko G, Heidenreich WF, et al. Thyroid exposures of children and adolescents due to the Chernobyl accident: the resulting cancer risk. In: Thomas G, Williams ED, Karaoglou A (eds). Radiation and Thyroid Cancer. Singapore: World Scientific, 1999:97-105

8 Cardis E, Kesminiene A, Ivanov V, et al. Risk of thyroid cancer after exposure to ${ }^{131} \mathrm{I}$ in childhood. J Natl Cancer Inst 2005;97:724-32

9 Fairlie I. Dispersal, deposition and collective doses after the Chernobyl disaster. Med Confl Surviv 2007;23:10-30

10 Sumner D. Health effects resulting from the Chernobyl accident. Med Confl Surviv 2007;23:31-45

11 Miller JD. Contentious calculations: controversy over Chernobyl's future cancer toll. Sci Am 2006;295:14

12 International Atomic Energy Agency. Basic Safety Standards, Safety Series No. 115. Vienna: IAEA, 1996. Available at http://www-pub.iaea.org/ MTCD/publications/PDF/SS-115-Web/Start.pdf (accessed 02/07/ 2007)

13 Barnett L. Psychosocial effects of the Chernobyl nuclear disaster. Med Confl Surviv 2007;23:46-57 